\title{
Properties Investigation of Epoxidized Sunflower Oil as Bioplasticizer for Poly (Lactic Acid)
}

\section{Mohamed BOUTI}

École Nationale Polytechnique: Ecole Nationale Polytechnique

\section{Ratiba IRINISLIMANE}

Université M'Hamed Bougara Boumerdès: Universite M'Hamed Bougara Boumerdes

Naima Belhaneche-Bensemra ( $\nabla$ naima.belhaneche@g.enp.edu.dz )

Ecole Nationale Polytechnique https://orcid.org/0000-0001-9315-8701

\section{Research Article}

Keywords: Poly(lactic acid), epoxidized sunflower oil, epoxidized soya bean oil, bioplasticizer

Posted Date: March 18th, 2021

DOl: https://doi.org/10.21203/rs.3.rs-297393/v1

License: (1) This work is licensed under a Creative Commons Attribution 4.0 International License.

Read Full License

Version of Record: A version of this preprint was published at Journal of Polymers and the Environment on June 1st, 2021. See the published version at https://doi.org/10.1007/s10924-021-02194-3. 


\section{Abstract}

This study aims to improve the ductility of poly (lactic acid) (PLA). For that purpose, bioblends based on PLA and epoxidized vegetable oils (EVO) as bioplasticizers were prepared. Commercial sunflower oil was epoxidized and epoxidized sunflower oil (ESO) was used as plasticizer for PLA. To investigate ESO potential as plasticizer for PLA, its plasticizing effect was compared with commercial epoxidized soya bean oil (ESBO). The plasticizers (ESO or ESBO) were respectively compounded with PLA at 10, 20, 30, and $40 \mathrm{wt} \%$. Mechanical (tensile and Shore D hardness), thermal (differential scanning calorimetry (DSC), thermogravimetric analysis (TGA)) and morphological properties (optical microscopy and scanning electron microscopy (SEM)) were characterized. The results showed that the addition of ESO or ESBO to PLA decreased tensile strength and tensile modulus compared to neat PLA but increased elongation at break for which an optimum $\left(9.02 \%, 15.55 \%\right.$ and $33.67 \%$ for $\mathrm{ESBO}, \mathrm{ESO}_{5.5 \%}$ and $\mathrm{ESO}_{6.5 \%}$ respectively) was reached at a content of $20 \mathrm{wt} \%$ of plasticizer. The structures of the obtained plasticized PLA were confirmed by FTIR spectroscopy. DSC showed a clear decrease in the glass transition temperature of PLA and SEM analysis proved successful modification on the PLA brittle morphology with addition of EVO. On the other hand, TGA results revealed significant increase in the thermal stability. Based on the results of this study, ESO exhibited promising results regarding

\section{Introduction}

Research in biodegradable polymers has received increased attention in recent years because of their wide application in environmental friendly packaging. The most popular and biodegradable polymers are aliphatic polyesters, such as polylactic acid (PLA), polycaprolactone (PCL), poly (butylene adipate terephthalate) (PBAT) and polyhydroxybutyrate (PHB).

PLA is a polyester that can be produced from lactic acid derived from renewable resources. It is one of the most frequently used biodegradable polymers, especially in packaging applications because of its high strength, high modulus, good transparency, processability, and biocompatibility. However, PLA is quite brittle, which limits its applications. Considerable efforts have been carried out to improve the properties of PLA so as to compete with low cost and flexible commodity polymers. These attempts include blending PLA with other polymers [1], modifying PLA with plasticizers [2, 3], or blending with mineral fillers composites [4].

Enhancement of the flexibility could be achieved by blending it with low molecular weight plasticizers such as citrate esters [5], polyethylene glycol [6], polypropylene glycol [7] and oligomeric lactic acid [8]. Nowadays, there is increasing interest in the use of natural-based plasticizers that are characterized by low toxicity and low migration. This group includes epoxidized triglyceride vegetable oils from soybean oil [9], cottonseed oil [10], castor-oil [11], sunflower oil [12], and fatty acid esters (FAEs) [13]. Epoxidized vegetable oils have received much attention because they act as reactive plasticizers through the reactivity between epoxy functional groups and the $-\mathrm{OH}$ and $-\mathrm{COOH}$ groups of PLA [14-17]. 
Sunflower oil is a renewable resource which was modified by epoxidation [18]. Epoxidized sunflower oil was used as not toxic and environment-friendly additive (thermal stabilizer and plasticizer) in polymer formulations and specially poly vinyl chloride [19-22].

In this study, commercial sunflower oil was epoxidized. The plasticizing effects of epoxidized sunflower oil (ESO) on the properties of PLA were investigated. Performances of ESO on PLA are compared to those of epoxidized soya bean oil (ESBO) in the same conditions.

\section{Experimental}

\subsection{Materials}

PLA (Nature Works 2002D) with an MFI $6.18 \mathrm{~g} / 10 \mathrm{~min}$, density $1.23, \mathrm{~T}_{\mathrm{g}} 63^{\circ} \mathrm{C}$ and $\mathrm{T}_{\mathrm{m}} 154{ }^{\circ} \mathrm{C}$, as used.

Sunflower oil is a commercial product from the company Cévital (Béjaia, Algeria). It was used as received. Epoxidized sunflower oil was especially prepared as described previously [10]. Its level of oxyrane oxygen (0.0) is $5.5 \%$ and $6.5 \%$. A commercial epoxidized soya bean oil (ESBO) from Akdeniz Kimya A.S. (Turkey) with 0.0 of $5.9 \%$ was used for comparison as plasticizer for PLA.

Formic acid (98\%) was obtained from Panreac Química SA, hydrogen peroxide (30 wt\%) and hydrogen bromide (40 wt\%) were purchased from Biochem Chemophama, glacial acetic acid (99.9\%) was purchased from ChemLab NV and chloroform analytical grade from Aldrich Co.

\subsection{Sunflower oil characterization}

Characterization of sunflower oil was carried out according to American Oil Chemists' Society (AOCS) Official Method. The acid value (AV), saponification value (SV) and iodine value (IV) were determined according to the AOCS Official Method CD 3A-63, AOCS Official Method CD 3C-91 and AOCS Official Method CD 1D-92, respectively. The viscosity was determined according to dynamic viscosity test method (ASTM D 445-79) using a DV-II + Pro Viscometer, Brookfeld Engineering Labs. Inc. Middleboro at $100 \mathrm{rpm}$ with S2, S1 spindles at different temperatures. The relative density was determined according to ASTM D891-09 Test Method B by means of a pycnometer, water content was measured by Karl Fischer titration. Characteristics of sunflower oil are given in Table 1.

Table 1 Main physicochemical properties of sunflower oil 


\begin{tabular}{|c|c|}
\hline Parameter & value \\
\hline Physical state & Yellow liquid \\
\hline Acid value (mg KOH.g $\left.{ }^{-1}\right)$ & $0.5 \pm 0.2$ \\
\hline Saponification value $\left(\mathrm{mg} \mathrm{KOH} \cdot \mathrm{g}^{-1}\right)$ & $191.9 \pm 0.2$ \\
\hline lodine value ( $\left(\mathrm{g} \mathrm{I}_{2} / 100 \mathrm{~g}\right.$ oil) & $129.2 \pm 0.5$ \\
\hline Relative density $\left(\mathrm{kg} \cdot \mathrm{m}^{-3}\right)$ & $920.7 \pm 0.5$ \\
\hline 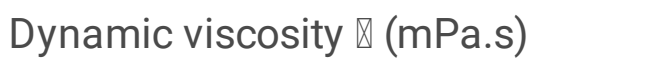 & $40.1 \pm 0.6$ \\
\hline
\end{tabular}

\subsection{Epoxidation of sunflower oil}

Sunflower oil was used as received. The reaction of epoxidation was carried out according to $\mathrm{C}=\mathrm{C}$ double bond/formic acid/hydrogen peroxide molar ratio of $1 / 0.5 / 1.5$, the unsaturated compound is mixed with hydrogen peroxide and acetic acid, and the peracid is consumed as it is formed. Sunflower oil and formic acid were poured in a three-necked flask fitted with a mechanical stirrer; the flask was immersed in a water bath with water temperature of $40{ }^{\circ} \mathrm{C} \pm 2$ and moderate speed of $1500 \mathrm{rpm}$. To start the epoxidation, hydrogen peroxide solution $\left(\mathrm{H}_{2} \mathrm{O}_{2}, 30 \mathrm{wt} \%\right)$ was charged dropwise over a period of 15 min to avoid overheating. The reaction continued for a further 4 hours. After that, the oil and aqueous phases were decanted; the organic phase was washed, rinsed and neutralized successively with heated distilled water. A succinct scheme, without taking into consideration the undesired consecutive reactions due to the attack (ring opening) is given in Scheme 1. Titration of oxirane groups (oxirane index) was determined using analytical method [23]; this operation was repeated three times. After the best conditions were determined, two samples of ESOs with 0.0 of 5.5 and $6.5 \%$ were prepared.

The characteristics of ESBO and ESO are listed in Table 2.

Table 2 Properties of ESBO, $\mathrm{ESO}_{5.5 \%}$ and $\mathrm{ESO}_{6.5 \%}$

\begin{tabular}{|llll|}
\hline Sample composition & $\mathrm{ESBO}$ & $\mathrm{ESO}_{5.5 \%}$ & $\mathrm{ESO}_{6.5 \%}$ \\
\hline Oxirane Oxygen (\%) & 5.9 & 5.5 & 6.5 \\
\hline Acid value $\left(\mathrm{mg} \mathrm{KOH.g}{ }^{-1}\right)$ & $6.2 \pm 0.2$ & $5.6 \pm 0.1$ & $5.1 \pm 0.2$ \\
\hline lodine value $\left(\mathrm{g} \mathrm{I}_{2} / 100 \mathrm{~g}\right.$ oil) & $82.5 \pm 1.5$ & $106.7 \pm 0.2$ & $105.3 \pm 0.4$ \\
\hline
\end{tabular}

\subsection{Preparation of plasticized poly (lactic acid)}


Plasticized PLA films were prepared by solution casting method. PLA was first dried overnight in an oven at $40^{\circ} \mathrm{C}$. Plasticized PLA films were obtained by dissolving the required amount of PLA in chloroform at room temperature in a stirred flask for $1 \mathrm{~h}$, followed by the addition of the plasticizer, with a dropper and continued stirring for 3 at 4 hours. The PLA / plasticizer mixtures were poured into ceramic dishes with appropriate dimensions $\left(50 \times 100 \times 60 \mathrm{~mm}^{3}\right)$. Chloroform was evaporated. The plasticizers $($ ESO $(0.0=$ 5.5 or $6.5 \%$ ) or ESBO) were respectively compounded with PLA at 10, 20, 30, and 40 wt \%.

\subsection{Plasticized PLA characterization}

\subsubsection{Tensile testing}

Tensile properties were performed at room temperature using MTS Criterion Electromechanical Universal Test System, Model 41 Series 40. The $1 \mathrm{~mm}$ plasticized PLA sheets were cut into a dumbbell shape based on ASTM D638 (type V) standard. The test was conducted with a $1.0 \mathrm{kN}$ load cell and a constant crosshead speed of $10 \mathrm{~mm} \cdot \mathrm{min}^{-1}$. Tensile strength, tensile modulus, and elongation at break were measured. The results obtained represent the average of three measurements for each sample at least.

\subsubsection{Hardness Shore D characterization}

The shore D hardness test was carried out according to ISO 868 using a Bareiss Shore D Tester. Sheets of $4 \mathrm{~mm}$ thickness were used for hardness measurements. Three measurements were made on each sample type.

\subsubsection{Fourier transform infrared spectroscopy analysis}

In order to identify the surface functional groups on the prepared samples, Fourier transform infrared spectroscopy was carried out on a Nicolet iS10 spectrophotometer at high resolution and over 32 scans in the wavelength range between 4000 and $400 \mathrm{~cm}^{-1}$.

\subsubsection{Differential scanning calorimetry analysis}

Differential scanning calorimetry was conducted with a NETZSCH STA 409PC/PG instrument in nitrogen atmosphere; the heating program was from 20 to $200{ }^{\circ} \mathrm{C}$ at a heating rate of $10{ }^{\circ} \mathrm{C} . \mathrm{min}^{-1}$. OriginPro 2018 was used to analyze the curves.

\subsubsection{Thermogravimetric analysis}

Thermogravimetric analysis measurements were performed using a NETZSCH STA 409PC/PG instrument from 20 to $500{ }^{\circ} \mathrm{C}$ at a heating rate of $10{ }^{\circ} \mathrm{C} \cdot \mathrm{min}^{-1}$ in nitrogen atmosphere.

\subsubsection{Optical microscopy analysis}

Samples were analyzed by optical microscopy with an OPTIKA® type apparatus piloted by a computer at a magnification of 100 times using a 10/0.40 compound lens and transmitted light. 


\subsubsection{Scanning electron microscopy analysis}

The fracture surfaces of tensile failed sample were studied under a FEI Quanta 650 scanning electron microscopy (SEM) instrument.

\section{Results And Discussion}

\subsection{Mechanical properties}

Tensile properties are the most frequently used indicator of changes caused by plasticization. Results of the tensile measurements, including tensile strength, tensile modulus and elongation at break are displayed graphically in Figures 1, 2 and $\mathbf{3}$. Figure 1 shows that the addition of gradual amounts of ESBO, $\mathrm{ESO}_{5.5 \%}$ and $\mathrm{ESO}_{6.5 \%}$ plasticizers into PLA matrix improved the tensile strength of PLA. At $20 \mathrm{wt} \%$, the most efficient plasticizer is the $\mathrm{ESO}_{6.5 \%}$ that reduced tensile strength from $13.3 \mathrm{MPa}$ to $8 \mathrm{MPa}$. At low loading of $10 \mathrm{wt} \%$ as at high loading of $40 \mathrm{wt} \%$, there were no significant differences in tensile strength between plasticizers.

Tensile strength of plasticized PLA decreased with increasing amount of plasticizers. At higher plasticizer loading, only a part of the plasticizer was located in the interfacial area, while the rest is penetrated into the polymer mass, separating chains and thus reducing intermolecular forces between them and consequently reducing the tensile strength of the plasticized PLA [24-25].

The shape of tensile modulus curves is analogous to that of tensile strength. The decrease of tensile modulus indicates an increase in samples' flexibility due to the diminution of chains interactions induced by the presence of plasticizers.

Neat PLA exhibited an elongation at break of $5 \%$ (Figure 3). The addition of plasticizers increased elongation at break of PLA. An optimum (9.02\%, $15.55 \%$ and $33.67 \%$ for $\mathrm{ESBO}, \mathrm{ESO}_{5.5 \%}$ and $\mathrm{ESO}_{6.5 \%}$ respectively) is reached at a content of $20 \mathrm{wt} \%$ of plasticizer. . Beyond that, the addition of

An optimum is reached at a content of $20 \%$ by weight of plasticizer.Un optimum est atteint à une teneur de $20 \%$ en poids de plastifiant. Elongation at break is defined as the ability of film to deform before finally breaking. This parameter helps to determine the flexibility and stretch ability of films. Elongation of polymeric materials depends on the mobility of their molecular chains. The increasing in films elongation can be explained by the fact that plasticizers decrease the intermolecular bonds between polymer chains and substitute them with hydrogen bonds formed between plasticizer and polymer chains. Such disruption and reconstruction of polymer chains interactions reduce the rigidity and promote the flexibility of films by allowing more chains mobility $[26,27]$.

Figure 4 shows the evolution of Shore $D$ hardness as a function of plasticizers contents (ESBO and ESO). The addition of plasticizers leads to softer materials with decreasing hardness as the plasticizer content increases. Nevertheless, the best efficiency can be observed for $\mathrm{PLA} / \mathrm{ESO}_{6.5 \%}$ by a decrease from 71 to 46 
at a level of $20 \mathrm{wt} \%$. These results are in total agreement with previous mechanical characterization, thus indicating the high efficiency of $\mathrm{ESO}_{6.5 \%}$ versus $\mathrm{ESO}_{5.5 \%}$ and $\mathrm{ESBO}$ for PLA plasticization.

According to the results of mechanical characterization, the use of $20 \mathrm{wt} . \%$ EVO reduced the intermolecular interactions between the polymeric chains and increased their mobility improving the flexibility and plastic deformation of PLA.

The most efficient plasticizer is $\mathrm{ESO}_{6.5 \%}$ at $20 \mathrm{wt} \%$ due to more important intermolecular interactions with PLA. In the rest of this study the effect of plasticizers at $20 \mathrm{wt} \%$ was investigated.

\subsection{FT-IR spectroscopy}

FT-IR spectroscopy was used to control the known functional group interactions of PLA with epoxidized vegetable oils and compare different plasticized PLA. Yin et al. [28] stressed that when two or more substances are mixed, physical blends versus chemical interactions are reflected by changes in the characteristic spectral bands. Figure 5 shows the FT-IR spectra of PLA in absence and presence of $20 \mathrm{wt}$ $\%$ of $\mathrm{ESBO}^{\mathrm{ESO}} \mathrm{E}_{5.5 \%}$ or $\mathrm{ESO}_{6.5 \%}$ from 500 to $4000 \mathrm{~cm}^{-1}$.

Ester group of PLA exhibits characteristic peaks at 1748,1187 and $1090 \mathrm{~cm}^{-1}$ corresponding respectively to $\mathrm{C}=\mathrm{O}$ stretching vibration, the asymmetrical valence vibrations of $\mathrm{C}-\mathrm{O}-\mathrm{C}$ and symmetrical valence vibrations of C-O-C of the aliphatic chain as Ristić and al. reported [29]. Changes in the position and intensity of these peaks were observed for the blends materials. The peak at $871 \mathrm{~cm}^{-1}$ can be assigned to the amorphous phase, while the peak at $756 \mathrm{~cm}^{-1}$ can be assigned to the crystalline phase as reported by Younes and Cohn [30]. Similar findings were reported by Auras and al. [31].

A relatively small peak at approximately $3500 \mathrm{~cm}^{-1}$ is visible for neat PLA due to the presence of hydroxyl groups. The FTIR spectra indicate that there are interactions between PLA and plasticizers. The characteristic peak of PLA at $1748 \mathrm{~cm}^{-1}$ has neutralized at $1752 \mathrm{~cm}^{-1}$ with the incorporation of plasticizers, and the peak at $3465 \mathrm{~cm}^{-1}$ was shifted to a broad peak at $3500 \mathrm{~cm}^{-1}$. Hydrogen bonding could occur between the carbonyl group (from ester linkage) in PLA and the epoxy group in plasticizers $[32$ 33]. Proposed possible sites for interactions between PLA and ESO are shown in Scheme 2.

\subsection{Differential scanning calorimetry investigation}

DSC is a very useful technique to study the glass transition temperature, crystallization temperature, and melting behavior. DSC thermograms of neat and plasticized PLA are shown in Figure 6.

Neat PLA showed a clear $\mathrm{T}_{\mathrm{g}}$ at $71.81^{\circ} \mathrm{C}$. The addition of $20 \mathrm{wt} \%$ of $\mathrm{ESBO}, \mathrm{ESO}_{5.5 \%}$ and $\mathrm{ESO}_{6.5 \%}$ decreased $\mathrm{T}_{\mathrm{g}}$ to $69.07^{\circ} \mathrm{C}, 70.31^{\circ} \mathrm{C}$ and $68.45^{\circ} \mathrm{C}$ respectively indicating that these plasticizers are miscible with PLA. With similar loading of plasticizers incorporated, $\mathrm{ESO}_{6.5 \%}$ exhibited relatively the most important effect on $T_{g}$ which indicates the best plasticizing effect. This decrease in $T_{g}$ can be explained on the base of increased mobility of the soft segments because of the penetration of plasticizers molecules into PLA 
hard segments [35]. The incorporation of plasticizers at various loadings did not result in any trace of separate melting or crystallization of EVO, indicating that the phase separation of EVO did not occur.

Furthermore, cold-crystallization was chosen as a crystallization method because it leads to a more intense spherulite nucleation resulting in shorter crystallization time and smaller spherulite sizes [35]. Figure 6 shows that neat PLA present a cold-crystallization temperature $\left(T_{c C}\right)$ at about $124.11^{\circ} \mathrm{C}$. $T_{c C}$ of PLA decreased by the addition of plasticizers, which suggests that plasticizer enhanced the ability to cold-crystallization of PLA. It is apparent that the $\left(T_{c c}\right)$ of PLA decreased with plasticizers addition, in parallel with the shift in $\mathrm{T}_{\mathrm{g}}$. The $\mathrm{T}_{\mathrm{cc}}$ decreased to $113.40{ }^{\circ} \mathrm{C}, 115.06{ }^{\circ} \mathrm{C}$ and $108.43^{\circ} \mathrm{C}$ for ESBO, $\mathrm{ESO}_{5.5}$ and $\mathrm{ESO}_{6.5}$ respectively. The significant drop of $\mathrm{T}_{\mathrm{cc}}$ and the decrease in $\mathrm{T}_{\mathrm{g}}$ indicates that the $\mathrm{EVO}$ are compatible with PLA. The decrease of Tcc and Tg of PLA occurred because of enhanced chains mobility with the plasticizer content [36]. Enhanced chain mobility increased the rate of crystallization, which allowed PLA to crystallize at lower temperature [37].

Neat PLA showed an endothermic peak of melting, $T_{m}=145.68^{\circ} \mathrm{C}$. A minor decrease in the melting temperature $\left(3.10^{\circ} \mathrm{C}\right.$ for PLA/ESBO, $1.57^{\circ} \mathrm{C}$ for PLA/ESO $5.5 \%$ and $0.95^{\circ} \mathrm{C}$ for PLA/ESO $6.5 \%$ ) was observed, indicating that the melting temperature of PLA was not greatly affected by the addition of plasticizers.

\subsection{Optical microscopy analysis}

To give a clearer view of surface modification of PLA and PLA/EVO blends, surfaces were characterized by optical microscopy. Figures 7(a) to (d) show the optical images of neat PLA, PLA/ESBO, PLA/ESO $5.5 \%$ and PLA/ESO $6.5 \%$. Neat PLA (Fig. 10(a)) displays smooth surface as compared with PLA/EVO blends while morphology of plasticized samples is heterogeneous and displays a skin-core distribution. EVO plasticizers are located below PLA skin as droplets in the polymer as it is clearly showed in Figures 7(b) to $\mathbf{7 ( d ) . ~ T h e s e ~ d r o p l e t s ~ c a u s e ~ t h e ~ i m p r o v e m e n t ~ o f ~ t h e ~ m e c h a n i c a l ~ p r o p e r t i e s . ~}$

\subsection{Scanning electron microscopy analysis}

Scanning electron microscopy analysis shows the surface morphology of the fractured tensile specimens and the state of dispersion of the epoxidized vegetable oils in the PLA matrix. A typical fracture surface of PLA exhibits smooth, homogeneous and a flat surface, corresponding to brittle crack growth behavior [3]. The addition of $20 \mathrm{wt} \%$ of epoxidized vegetable oils to PLA results in a significant change in morphology with improved adhesion and interfacial dispersion (Figures $\mathbf{8}(\mathbf{b})$ to (d)). The incorporation of 20 w\% EVO didn't create a brittle fracture, as observed in the neat PLA. Evident signs of plasticization were observed in EVO/PLA samples. However, the presence of fibrils and microvoids was observed indicating the formation of EVO rich phase in PLA matrix by phase separation [38].

\subsection{Thermogravimetric analysis}

The study of plasticized polymers must take into account the impact of the plasticizer on the thermal stability. The thermal degradation of plasticized PLA was investigated by thermogravimetric analysis. 
Figures 9(a) and (b) illustrate, respectively, the weight loss and the weight loss derivative of PLA/EVO samples. The corresponding data are given in Table 3.

The thermal stability of a polymeric material depends on the inherent characteristics of the macromolecules as well as on the molecular interactions between the different molecules. The chain cleavage or the bond dissociation of the macromolecules takes place when the supplied thermal energy exceeds the bond dissociation energy of the respective chemical bonds [34]. It is observed that the degradation onset temperatures of PLA/ESBO $\left(290.70^{\circ} \mathrm{C}\right), \mathrm{PLA} \mathrm{ESO}_{5.5 \%}\left(292.20^{\circ} \mathrm{C}\right)$ and PLA/ESO $6.5 \%$ $\left(291.20^{\circ} \mathrm{C}\right)$ are higher than that of neat PLA $\left(280.40^{\circ} \mathrm{C}\right)$. Hydrogen bonding between PLA and EVO increased the thermal stability of plasticized PLA. On the other hand, the weight loss of PLA in presence of $\mathrm{ESO}_{5.5 \%}(88.39 \%)$ or $\mathrm{ESO}_{6.5 \%}(88.02 \%)$ is similar to that of PLA $(86.62 \%)$ and lower than that of PLA in presence of ESBO $(90.10 \%)$.

Table 3 Thermogravimetric data of PLA in absence and presence of $20 \mathrm{wt} \%$ plasticizer.

\begin{tabular}{|lllll|}
\hline & PLA & PLAVESBO & PLAVESO $_{5.5 \%}$ & PLAVESO $_{6.5 \%}$ \\
\hline $\mathrm{T}_{\max }\left({ }^{\circ} \mathrm{C}\right)$, & 280.40 & $290.70^{\circ} \mathrm{C}$ & 292.20 & 291.20 \\
\hline Weight loss (\%) & 86.62 & 90.10 & 88.39 & 88.02 \\
\hline
\end{tabular}

$T_{\text {max }}$ : temperature of maximum weight loss

\section{Conclusion}

From the above results, the following conclusions can be derived:

Mechanical characterization of PLA/EVO samples showed a decrease in tensile strength and tensile modulus, but an increase in elongation at break. The optimum EVO loading with enhanced mechanical properties of PLA was $20 \mathrm{wt} \%$. $\mathrm{ESO}_{6.5 \%}$ was the most effective plasticizer due to more hydrogen bonds with hydroxyl groups of PLA. Furthermore, it exhibited the most important decrease of the glass transition temperature of plasticized PLA. SEM analysis showed successful modification of the PLA brittle morphology with addition of EVO. On the other hand, TGA results revealed significant increase in the thermal stability.

Globally, the results showed that the performances of the epoxidized sunflower oil are similar to those of epoxidized soya bean oil.

Based on the results of this study, ESO exhibited promising results regarding the improvement of the brittleness and overall properties of PLA and can therefore be considered as a potential plasticizer.

\section{Declarations}




\section{ACKNOWLEDGEMENTS}

This work was supported by DGRSDT (Direction Générale de la Recherche Scientifique et du Développement Technologique, Algeria).

\section{References}

1. Chieng B W, Nor Azowa I, Wan Md Zin Wan Y, Mohd Z H (2013) Plasticized poly(lactic acid) with low molecular weight poly(ethylene glycol) : mechanical, thermal and morphological properties. J Appl Polym Sci 130(6):4576-4580. https://doi.org/10.1002/app.39742

2. Chieng B W, Nor Azowa I, Yoon Yee T, Yuet Ying L (2014) Epoxidized vegetable oils plasticized poly(lactic acid) biocomposites : thermal and morphology properties. Molecules 19(10):1602416038. https://doi.org/10.3390/molecules191016024

3. Silverajah V S G, Nor Azowa I, Wan Md Zin Wan Y, Mohd Z H, Hazimah A H, Chieng B W (2012) A comparative study on the mechanical, thermal and morphological characterization of poly(lactic acid)/epoxidized palm oil blend. J. Mol. Sci 13(5):5878-5898. https://doi.org/10.3390/ijms13055878

4. Chieng B W, Nor Azowa I, Wan Md Zin Wan Y (2012) Optimization of tensile strength of poly(lactic acid)/graphene nanocomposites using response surface methodology. Polymer plastics technology and engineering 51(8):791-799. https://doi.org/10.1080/03602559.2012.663043

5. Maiza M, Benaniba M T, Valérie M-N (2015) Plasticizing effects of citrate esters on properties of poly(lactic acid). J Polym Eng 36(4):371-380. https://doi.org/10.1515/polyeng-2015-0140

6. Yuna Y, Yan C, Jiawei R, Erping C, Xiaowei F, Weihong G (2015) Plasticizing effect of poly(ethylene glycol)s with different molecular weights in poly(lactic acid)/stratch blends. J Appl Polym Sci 132(16). https://doi.org/10.1002/app.41808

7. Kulnski Z, Piorkowska E, Gadzinowska K, Stasiak M (2006) Plasticization of poly(L-lactide) with poly(ropylene glycol). Biomacromolecules 7(7):2128-2135. https://doi.org/10.1021/bm060089m

8. Ambrosio-Martín J, Fabra M J, Lopez-Rubio A, Lagron J M (2014) An effect of lactic acid oligomers on the barrier properties of polylactide. J Mater Sci 49:2975-2986. https:// doi.org/10.1007/s10853013-7929-x

9. Cheng X, Laurent MM (2016) Epoxidized soybean oil-plasticized poly(lactic acid) films performance as impacted by storage. J Appl Polym Sci 133(12). https://doi.org/10.1002/app.43201

10. Carbonell-Verdu A, Dolores Samper M, Garcia-Garcia D, Sanchez-Nacher L, Balart R (2017) Plasticization effect of epoxidized cottonseed oil (ECSO) on poly(lactic acid). Industrial Crops and Products. 104:278-286. http://dx.doi.org/10.1016/j.indcrop.2017.04.050

11. Fei S, Haoyu X, Puyou J, Meng Z, Lihong H, Yonghong Z (2018) The effect of epoxidized acrylated castor oil (EACO) on soft poly(vinyl chloride) films as a main plasticizer. Pol J Chem Tech 20 (4), 1319. https://doi.org/10.2478/pjct-2018-0048

12. Boussoum MO, Atek D, Belhaneche-Bensemra N (2006) Interaction between poly(vinyl chloride) stabilized with epoxidized sunflower oil and food stimulants. Polym Degrad Stab 91(03):579-584. 
https://doi.org/10.1016/j.polymdegradstab.2005.05.036

13. Ferri JM, Samper M, Garcia-Sanguera D, Reig MJ (2016) Plasticizing effect of biobased epoxidized fatty acid esters on mechanical and thermal properties of poly(lactic acid). J Mater Sci 51(11):53565366. https://doi.org/10.1007/s10853-016-9838-2

14. Anakabe J, Zaldua Huici AM, Eceiza A, Arbelaiz A (2016) The effect of the addition of poly (styreneco-glycidyl methacrylate) copolymer on the properties of polylactide/poly (methyl methacrylate) blend. J Appl Polym Sci 133(37). https://doi.org/10.1002/app.43935

15. Broström J, Boss A, Chronakis IS (2004) Biodegradable films of partly branched poly (L-lactide)-copoly ( $\varepsilon$-caprolactone) copolymer : Modulation of phase morphology, plasticization properties and thermal depolymerization. Biomacromolecules 5(3):1124-1134. https:// doi.org/10.1021/bm049920q

16. Dai X, Xiong Z, Na H, Zhu J (2014) How does epoxidized soybean oil improve the toughness of microcrystalline cellulose filled polylactide acid composites? Compos Sci Technol 90:9-15. https://doi.org/10.1016/j.compscitech.2013.10.009

17. Mihai, M, Huneault, MA, Favis BD (2010) Rheology and extrusion foaming of chain-branched poly (lactic acid). Polym Eng Sci 50(3):629-642. https://doi.org/10.1002/pen.21561

18. Benaniba MT, Belhanache-Bensemra N, Gelbard G (2001) Stabilizing effect of epoxidized sunflower oil on the thermal degradation of poly (vinyl chloride). Polym Degrad Stab 74(3):501-505. https://doi.org/10.1016/S0141-3910(01)00170-7

19. Gallouze N, Belhaneche-Bensemra N (2008) Influence of polluted atmospheres on the natural aging of poly(vinyl chloride) stabilised with epoxidized sunflower oil. J Appl Polym Sci 110(4): 1973-1978. https://doi.org/10.1002/app.27731

20. Benaniba MT, Massardier-Nageotte V (2010) Evaluation effects of biobased plasticizer on the thermal, mechanical, dynamical mechanical properties, and permanence of plasticized PVC. J App Polym Sci 118(6):3499-3508. https://doi.org/10.1002/app.32713

21. Lardjane N, Belhaneche-Bensemra N, Massardier V (2013) Migration of new bio-based additives from rigid and plasticized PVC stabilized with epoxidized sunflower oil in soil. J Polym Res 20:209-219. https://doi.org/10.1007/s10965-013-0209-2

22. Chellil O, Belhaneche-Bensemra N, López García D, Fernández-García M, Benaniba MT (2019) Preparation of epoxidized sunflower oil metal soap derivatives and their use as heat stabilizers for polyvinyl chloride. Turk J Chem 43(2):582-593. 3906/kim-1806-31

23. AOCS (2017) Official Method Cd 9-57, oxirane oxygen in epoxidized materials.

24. Wypych G (2004) Handbook of Plasticizers, ChemTec Publishing, Ontario, Canada.

25. Díez-Pascual AM, Naffakh M, Gómez MA, Marco C, Ellis G, González-Domínguez JM, Ansón A, Martínez MT, Martínez-Rubi Y, Simard B, Ashrafı B (2009) The influence of a compatibilizer on the thermal and dynamic mechanical properties of PEEK/carbon nanotube composites. Nanotechnology 20(31). https://doi.org/10.1088/0957-4484/20/31/315707 
26. Muscat D, Adhikari B, Adhikari R, Chaudhary DS (2012) Comparative study of film forming behaviour of low and high amylose starches using glycerol and xylitol as plasticizers. J Food Eng 109(2):189201. https://doi.org/10.1016/j.jfoodeng.2011.10.019

27. Fishman ML, Coffin DR, Konstance RP, Onwulata Cl (2000) Extrusion of pectin/starch blends plasticized with glycerol. Carbohydrate Polymers 41:317-325.

28. Yin YJ, Yao KD, Cheng GX, Ma JB (1999) Properties of polyelectrolyte complex films of chitosan and gelatin. Polym Int 48:429-433.

29. Ristić IS, Tanasić J, Nikolić LB, Cakić SM, llić OZ, Radičević R, Budinski-Simendic ZJK (2011) The properties of poly(L-lactide) prepared by different synthesis procedure. J Polym Environ 19:419-430. https://doi.org/10.1007/s10924-011-0297-1

30. Hani Y. Cohn D (1988) Phase separation in poly(ethylene glycol)/poly(lactic acid) blends. Eur Polym J 24(8):765-773.

31. Auras R, Harte B, Selke S (2004) An overview of polylactides as packaging materials. Macromolecular Bioscience. 4(9):835-864. https://doi.org/10.1002/mabi.200400043

32. Xu Y-Q, Qu J-P (2009) Mechanical and rheological properties of epoxidized soybean oil plasticized poly(lactic acid). J Appl Polym Sci 112(6):3185-3191. https://doi.org/10.1002/app.29797

33. Yew GH, Mohd YAM, Mohd IZA, Ishiaki US (2005) Water absorption and enzymatic degradation of poly(lactic acid)/rice starch composites. Polym Degrad Stab 90(3):488-500.

https://doi.org/10.1016/j.polymdegradstab.2005.04.006

34. Ray D, Roy P, Sengupta S, Sengupta SP, Mohanty A K (2009) A study of dynamic mechanical and thermal behavior of starch/poly(vinylalcohol) based films. J Polym Environ 17:49-55. https://doi.org/10.1007/s10924-009-0116-0

35. Pluta M, Galeski A (2002) Crystalline and supermolecular structure of polylactide in relation to the crystallization method. J App Polym Sci 86:1386-1395.

36. Pillin I, Montrelay N, Grohens Y (2006) Thermo-mechanical characterization of plasticized PLA: Is the miscibility the only significant factor?. Polym 47(13):4676-4682.

https://doi.org/10.1016/j.polymer.2006.04.013

37. Kulinski K, Piorkowska E (2005) Crystallization, structure and properties of plasticized poly(L-lactide). Polym. 46(23):10290-10300. https://doi.org/10.1016/j.polymer.2005.07.101

38. Fathilah A, Yung-Wook C, Shin CK, Joon YY (2009) Thermal, mechanical and rheological properties of poly(alctic acid)/epoxidized soybean oil blends. Polym Bulletin 62:91-98. https://doi.org/10.1007/s00289-008-1012-9

\section{Figures}




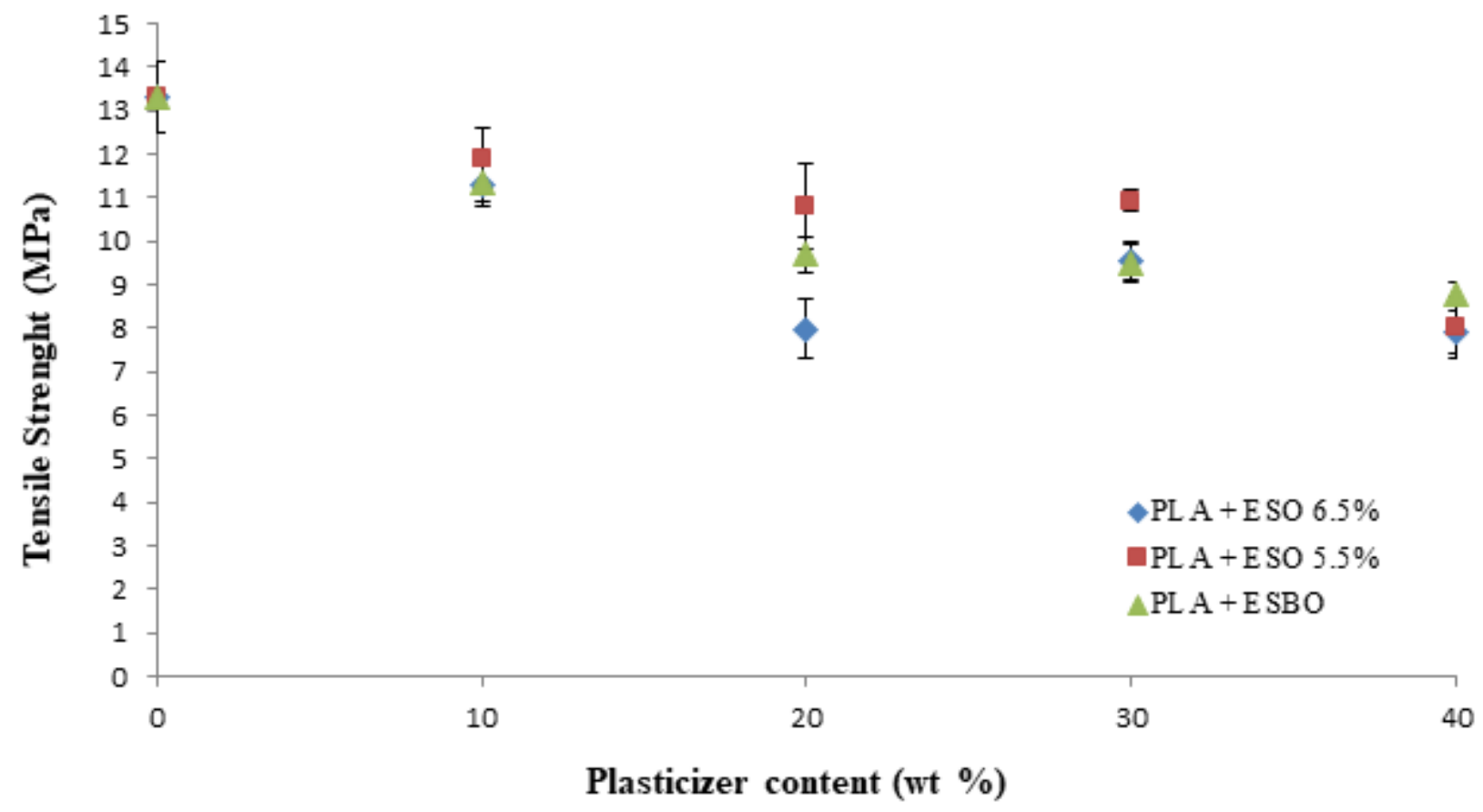

\section{Figure 1}

Variation of tensile strength of plasticized PLA with plasticizer content.

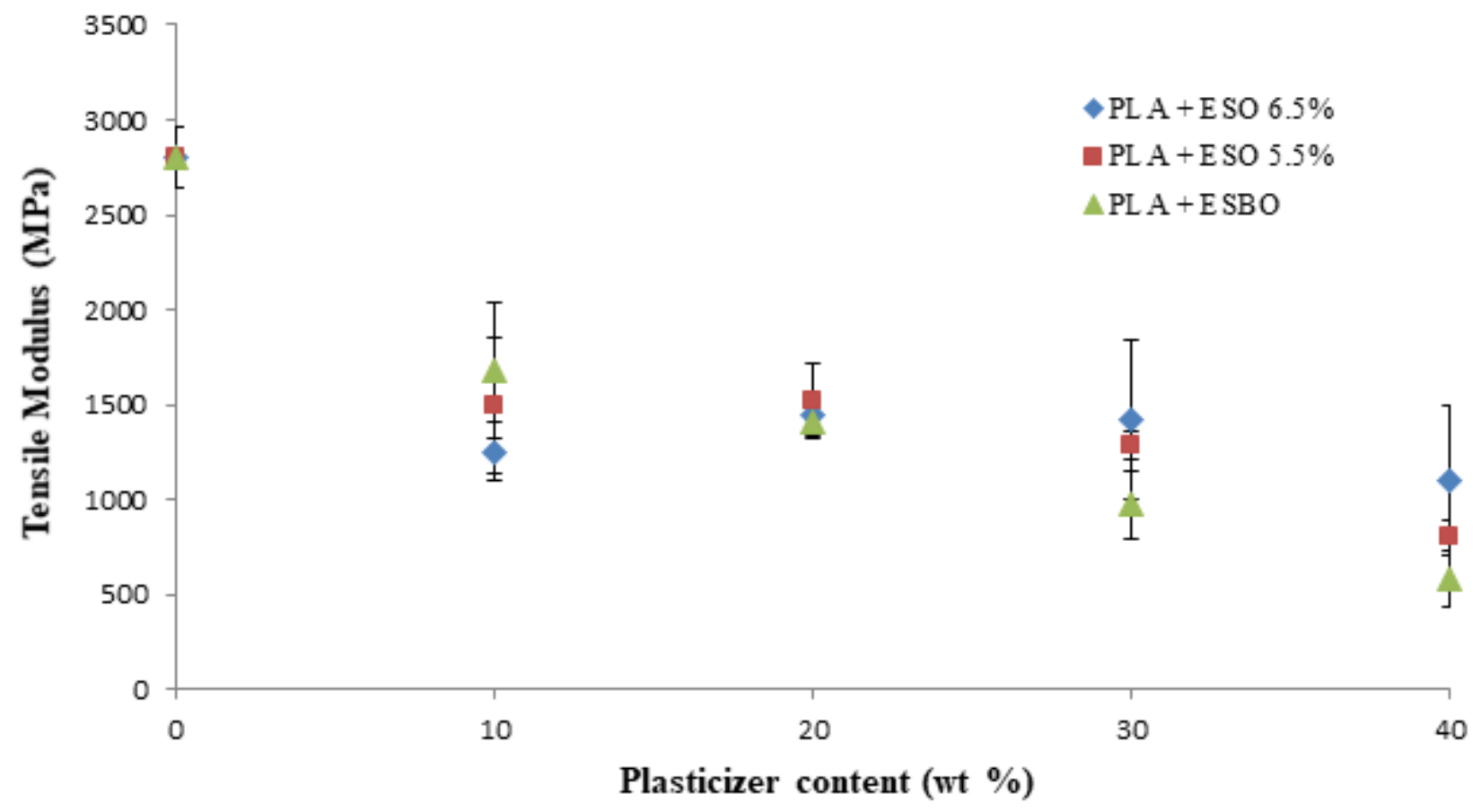

Figure 2

Variation of tensile modulus of plasticized PLA with plasticizer content. 


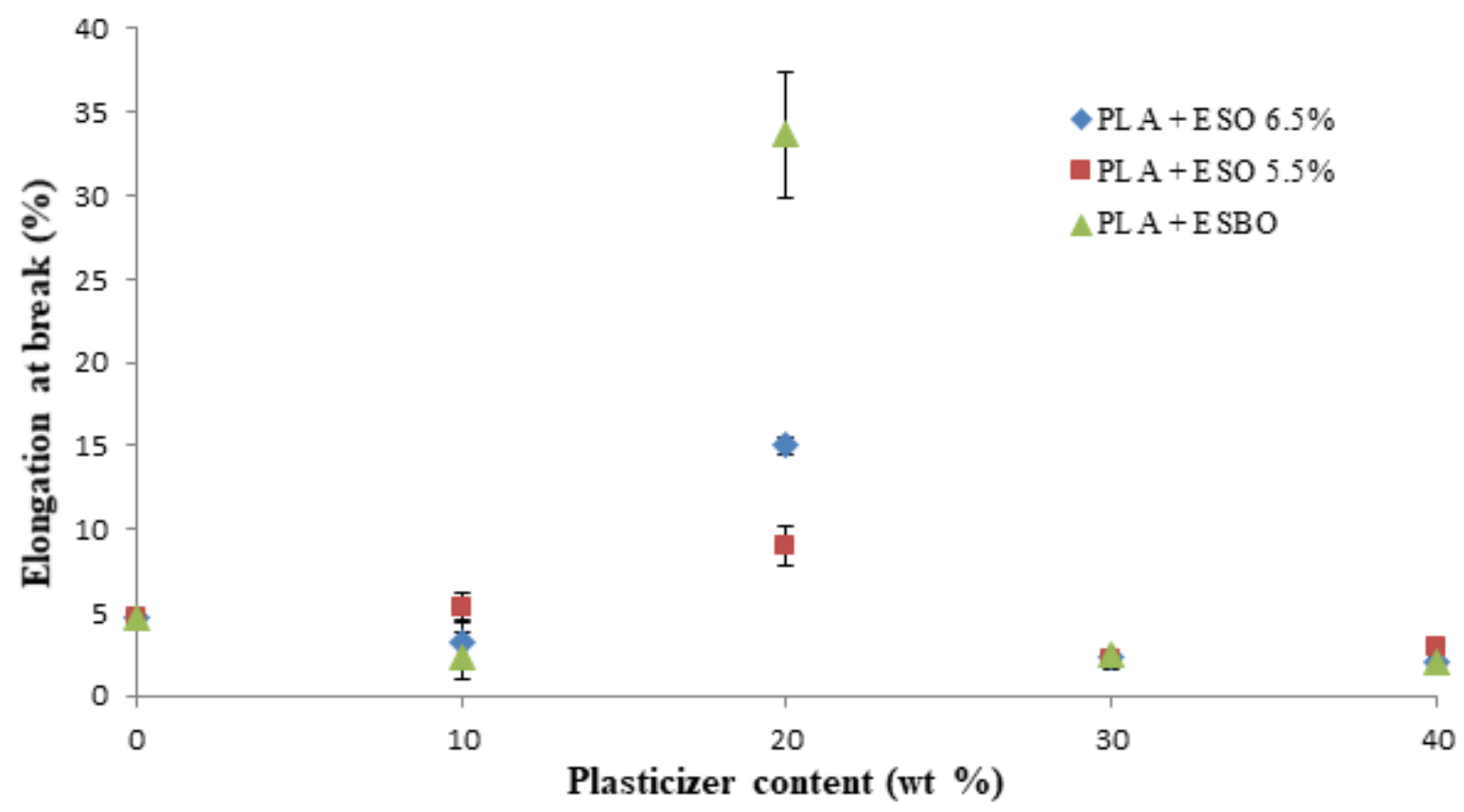

Figure 3

Elongation at break (\%) of plasticized PLA with plasticizer content.

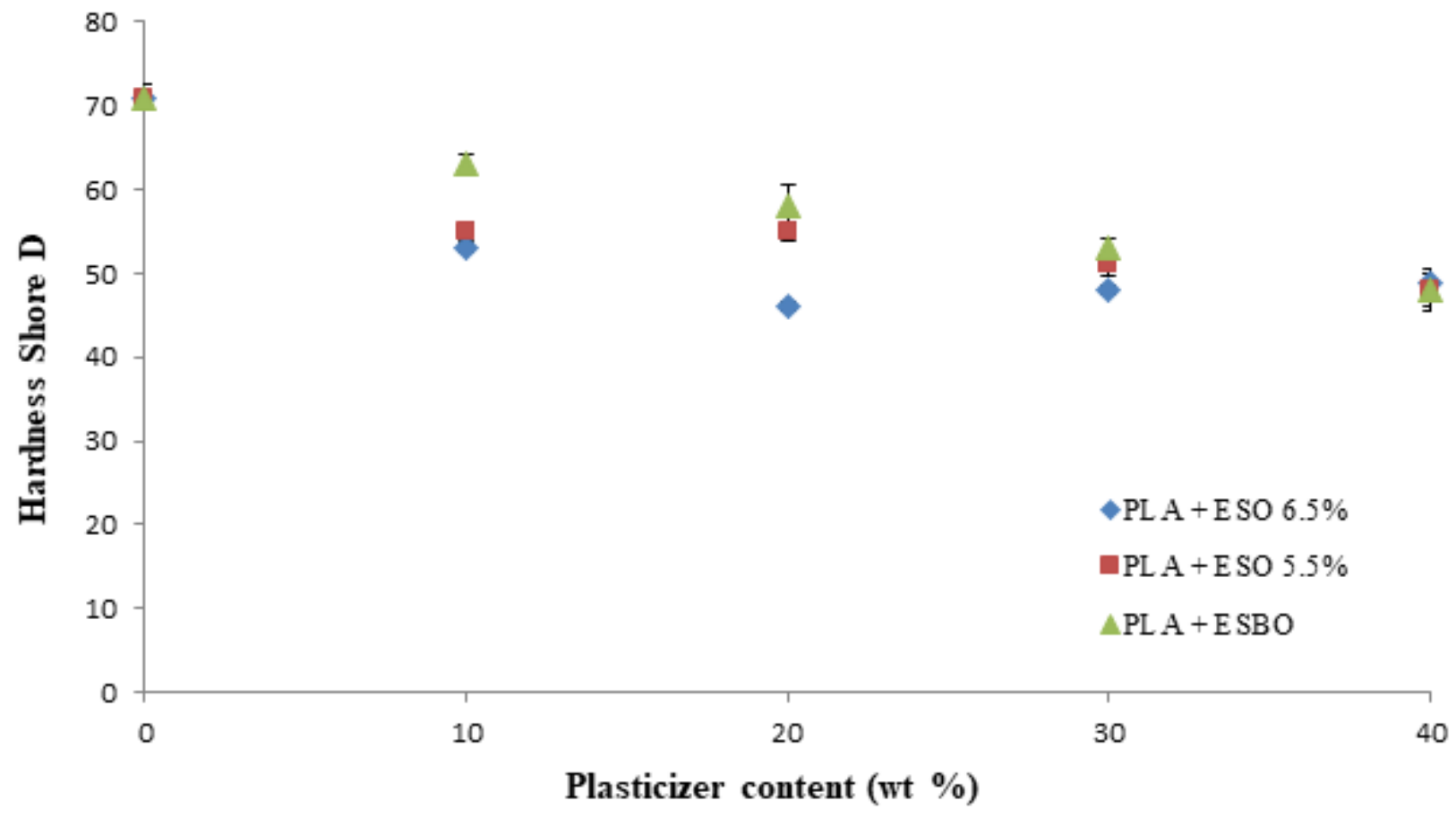

Figure 4

Evolution of Shore D hardness of plasticized PLA with plasticizers content. 


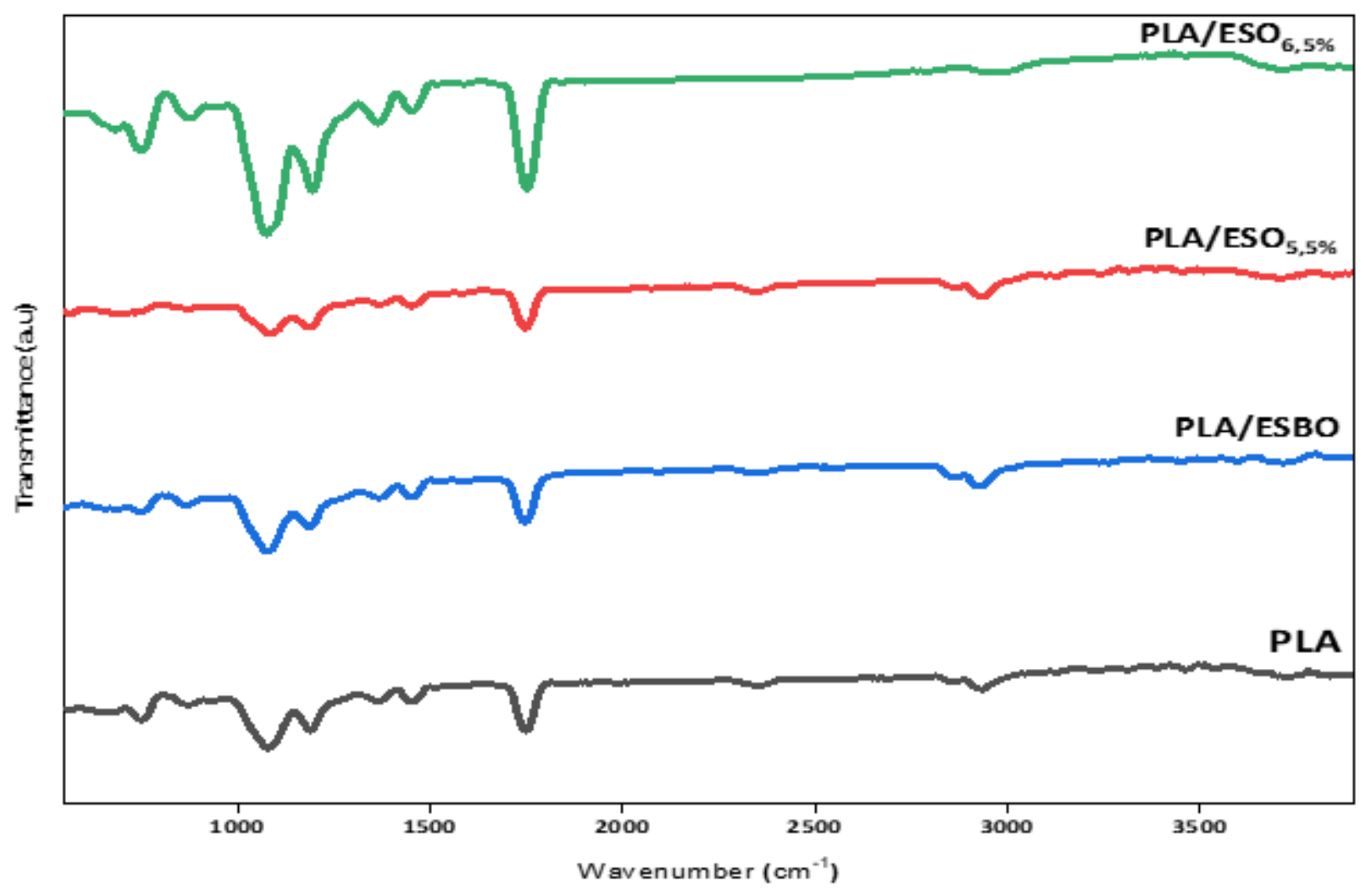

Figure 5

Infrared spectra of PLAP in absence and presence of $20 \mathrm{wt} \%$ plasticizer.

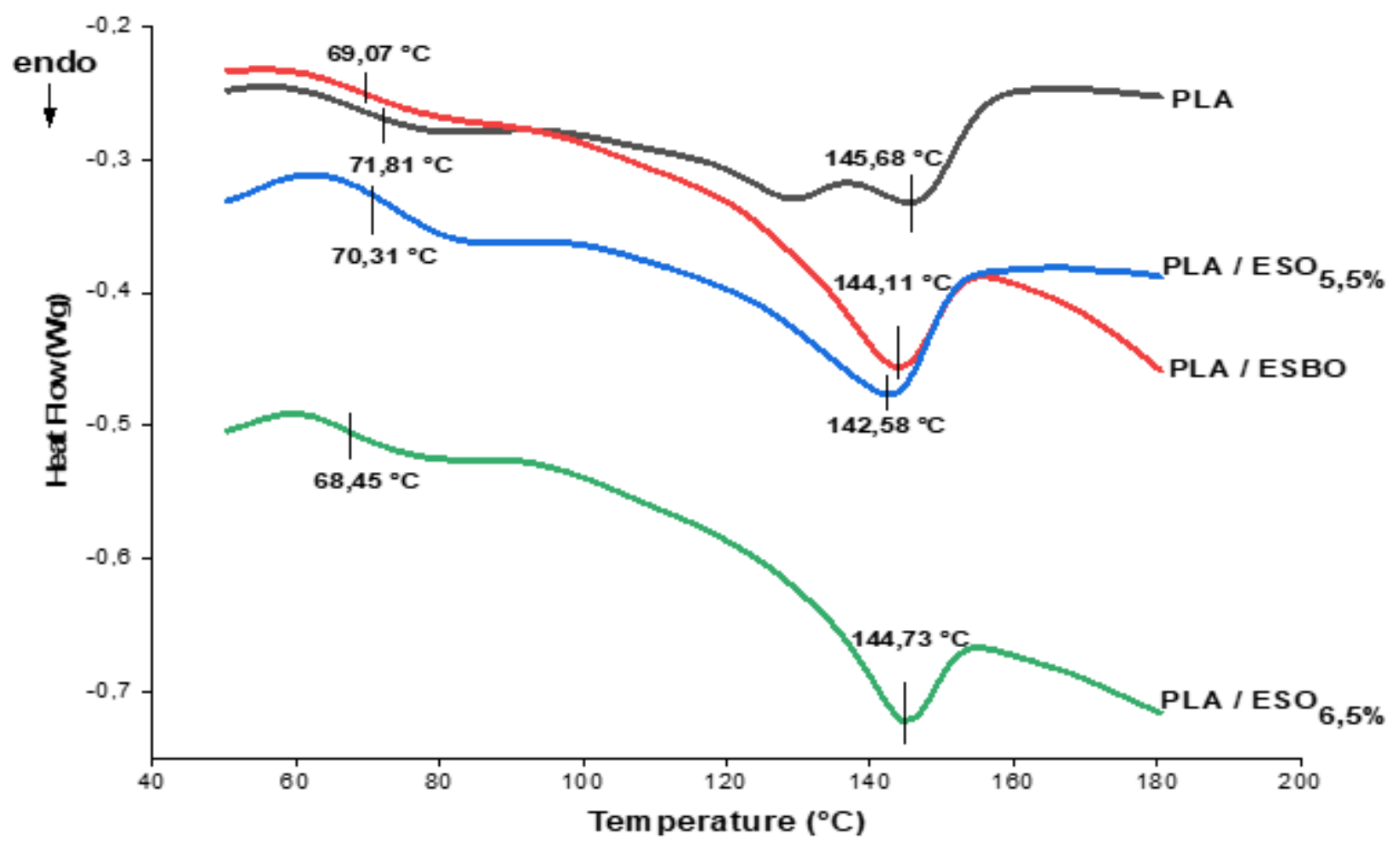

Figure 6 
DSC thermograms of PLA in absence and presence of 20 wt \% of ESBO or ESO.
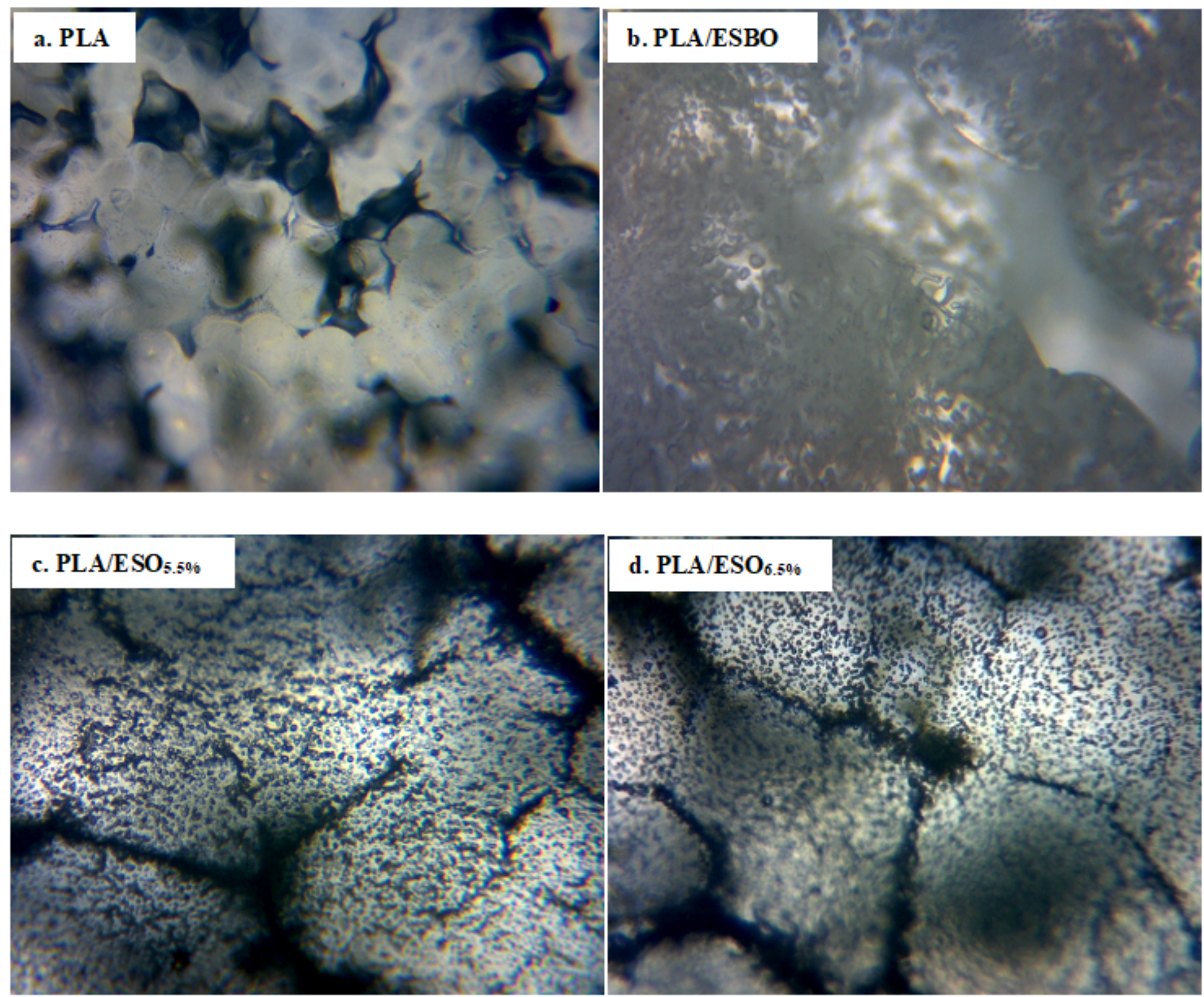

\section{Figure 7}

Optical microscopy images of PLA in absence (a) and presence of 20 wt \% of ESBO (b), ESO5.5\% (c) and ESO6.5\% (d). 

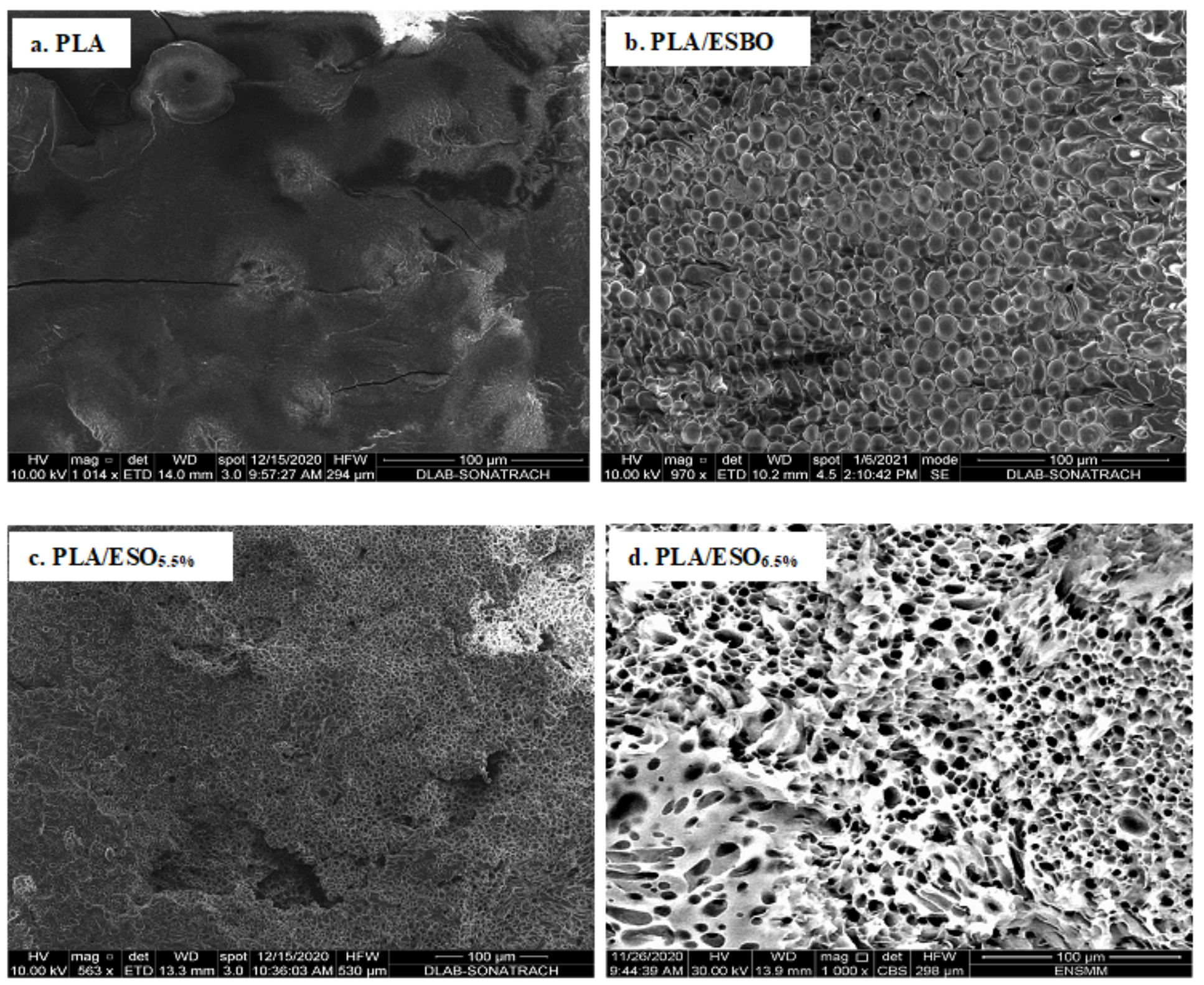

Figure 8

Scanning electron microscopy images of PLA in absence (a) and presence of 20 wt \% of ESBO (b), ESO5.5\% (c) and ESO6.5\% (d). 

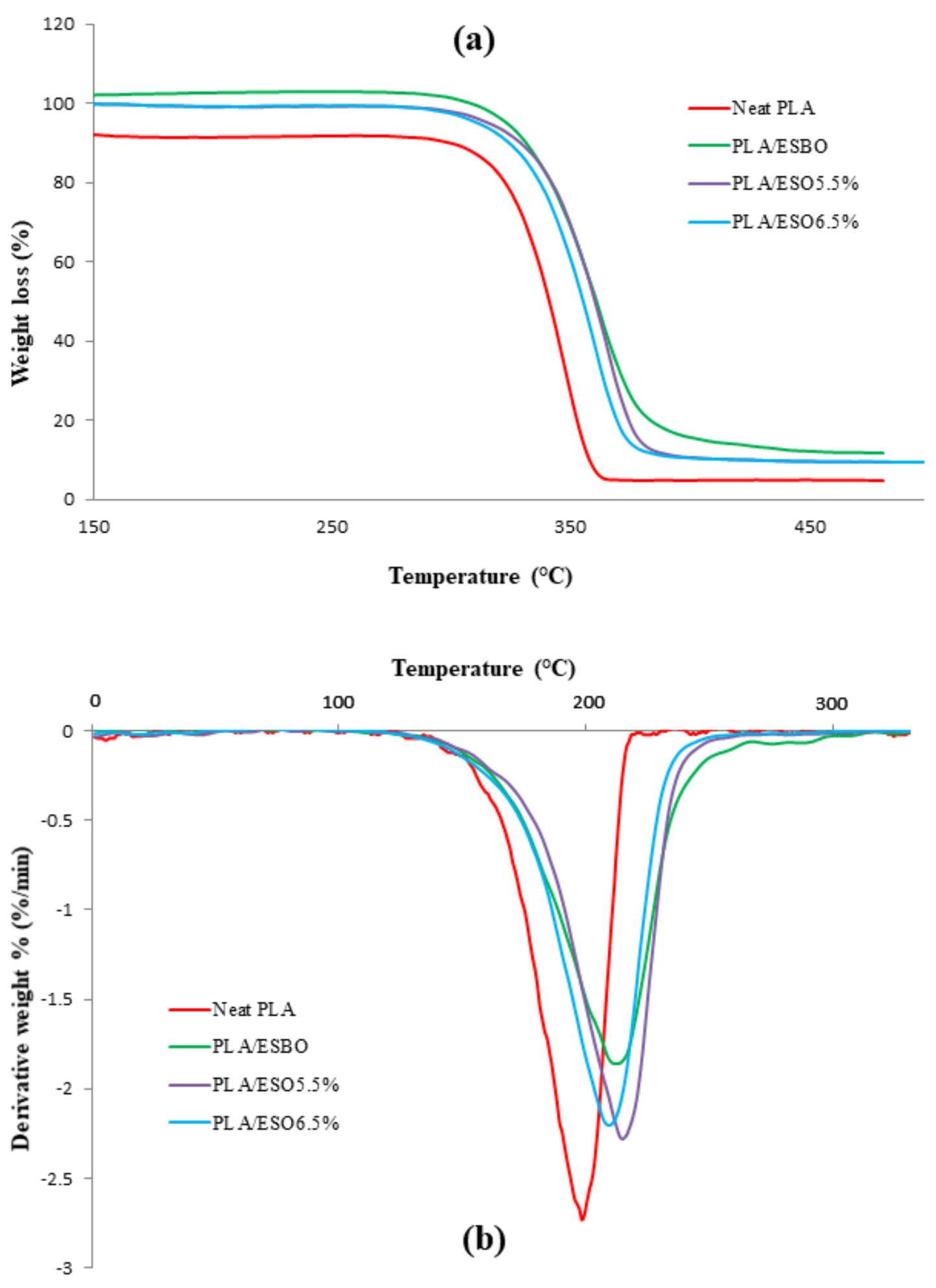

\section{Figure 9}

Thermogravimetric curves of PLA in absence and presence of $20 \mathrm{wt} \%$ of plasticizer: (a) Weight loss; (b) Derivative weight loss.

\section{Supplementary Files}


This is a list of supplementary files associated with this preprint. Click to download.

- Scheme01.png

- Scheme02.png 